\title{
Correction
}

\section{Correction: End-expiratory lung volume during mechanical ventilation: a comparison with reference values and the effect of positive end-expiratory pressure in intensive care unit patients with different lung conditions}

\author{
Ido G Bikker, Jasper van Bommel, Dinis Reis Miranda, Jan Bakker and Diederik Gommers
}

Department of Intensive Care Medicine, Erasmus MC, 's Gravendijkwal 230, 3015 CE Rotterdam, The Netherlands

Corresponding author: Diederik Gommers, d.gommers@erasmusmc.nl

Published: 15 December 2009

This article is online at http://ccforum.com/content/13/6/430

(c) 2009 BioMed Central Ltd

Following the publication of our article [1] we noticed that three of the figures were incorrectly numbered and positioned with respect to the figure legends.

The complete set of correct figures (Figure 1, 2, 3 and 4) follows below. Figures 2, 3 and 4 appeared incorrectly in the original article.
Critical Care 2009, 13:430 (doi:10.1186/cc8196)

\section{Reference}

1. Bikker IG, van Bommel J, Reis Miranda D, Bakker J and Gommers $\mathrm{D}$ : End-expiratory lung volume during mechanical ventilation: a comparison with reference values and the effect of positive end-expiratory pressure in intensive care unit patients with different lung conditions. Crit Care 2008, 12:R145.
Figure 1

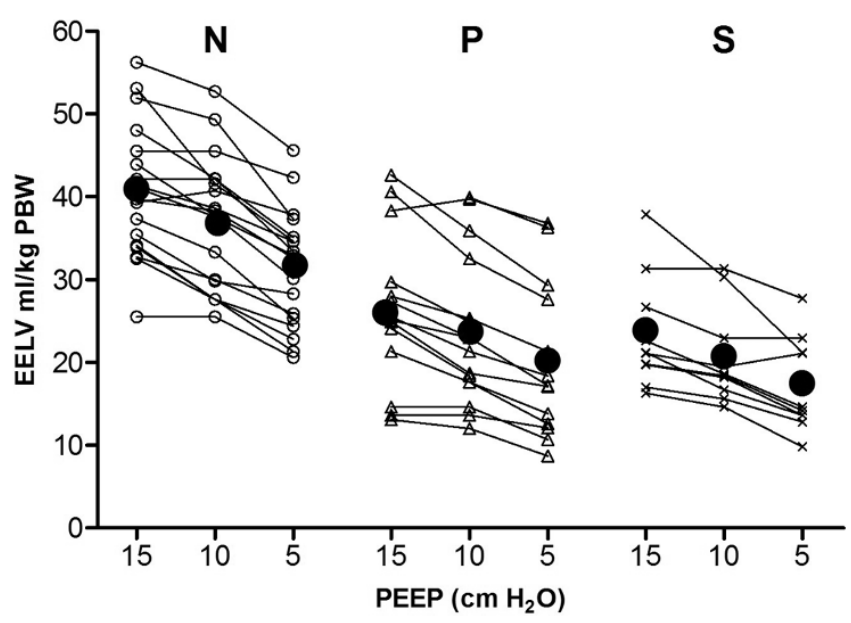

Progression of EELV in individual patients over three stepwise reductions in PEEP. Mean EELV values at each PEEP level are presented as black dots. Patients are divided according to the type of lung condition. Patients in group $\mathrm{N}$ had normal lungs, those in group $\mathrm{P}$ had a primary lung disorder, and those in group $S$ had a secondary lung disorder. EELV, end-expiratory lung volume; PBW, predicted body weight; PEEP, positive end-expiratory pressure.
Figure 2

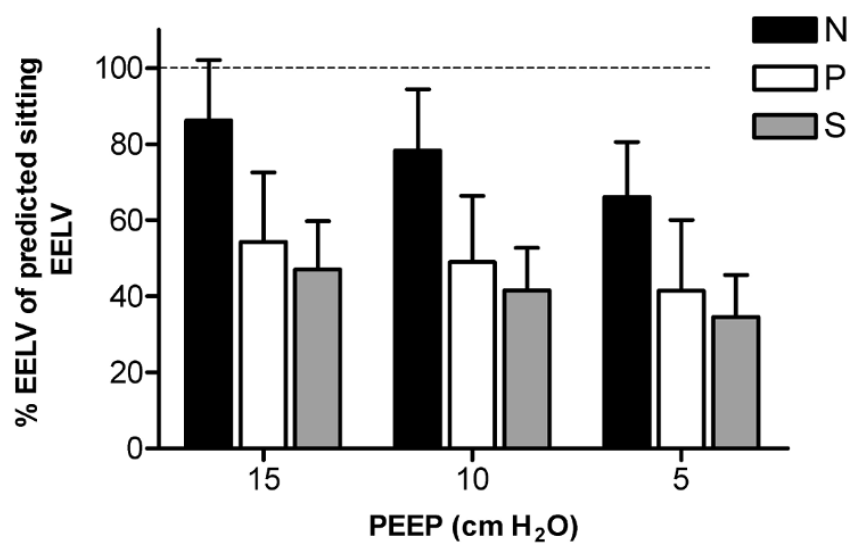

Measured EELV as percentage of predicted sitting FRC at three PEEP levels. The black dotted line represent predicted sitting FRC (100\%). Patients in group $\mathrm{N}$ had normal lungs, those in group $\mathrm{P}$ had a primary lung disorder, and those in group $\mathrm{S}$ had a secondary lung disorder. Values are expressed as mean \pm standard deviation. EELV, endexpiratory lung volume; $\mathrm{FiO}_{2}$, inspired oxygen fraction; $\mathrm{FRC}$, functional residual capacity; $\mathrm{PaO}_{2}$, arterial oxygen tension; PEEP, positive endexpiratory pressure. 
Figure 3

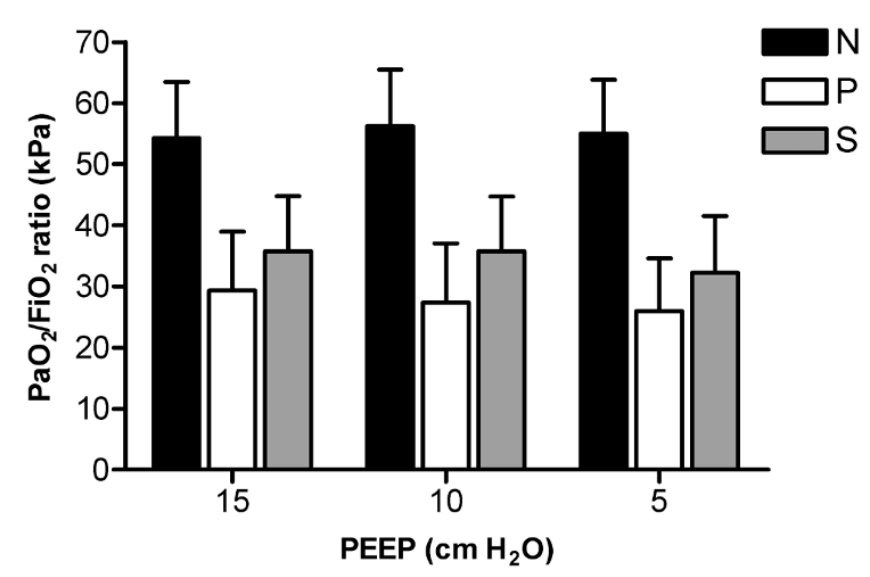

$\mathrm{PaO}_{2} / \mathrm{FiO}_{2}$ ratio in different types of lung conditions at three PEEP levels. Patients in group $\mathrm{N}$ had normal lungs, those in group $\mathrm{P}$ had a primary lung disorder, and those in group $\mathrm{S}$ had a secondary lung disorder. Values are expressed as mean \pm standard deviation. EELV, end-expiratory lung volume; $\mathrm{FiO}_{2}$, inspired oxygen fraction; $\mathrm{PaO}_{2}$, arterial oxygen tension; PBW, predicted body weight; PEEP, positive end-expiratory pressure.

Figure 4
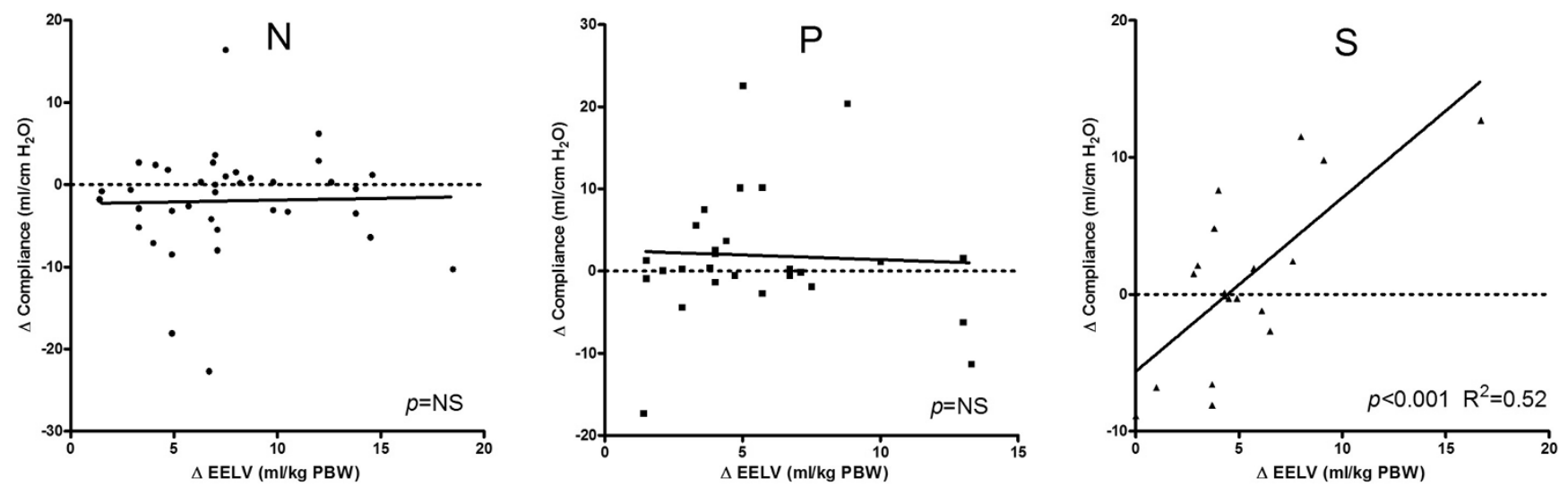

Correlation between change in EELV and change in dynamic compliance. Data are presented as the difference between the lowest PEEP level $\left(5 \mathrm{cmH}_{2} \mathrm{O}\right)$ and 10 or $15 \mathrm{cmH}_{2} \mathrm{O}$ PEEP. Patients in group $\mathrm{N}$ had normal lungs, those in group $\mathrm{P}$ had a primary lung disorder, and those in group $\mathrm{S}$ had a secondary lung disorder. EELV, end-expiratory lung volume; PEEP, positive end-expiratory pressure. 